\title{
Multi-Technique Analysis of the Hydration in
}

\section{Three Different Copper Carboxylate Metal-Organic Frameworks}

Angela Terracina ${ }^{1,2}$, Lauren N. McHugh ${ }^{3}$, Michela Todaro ${ }^{1}$, Simonpietro Agnello ${ }^{1}$, Paul S. Wheatley ${ }^{3}$, Franco M. Gelardi ${ }^{1}$, Russell E. Morris ${ }^{3}$, and Gianpiero Buscarino ${ }^{1, @}$

${ }^{1}$ Dipartimento di Fisica e Chimica - Emilio Segrè, Università di Palermo, Palermo 90123, Italy

${ }^{2}$ Dipartimento di Fisica e Astronomia, Università di Catania, Palermo 95123, Italy

${ }^{3}$ EaStCHEM School of Chemistry, University of St Andrews, Purdie Building, St Andrews, KY16 9ST, United Kingdom

@,gianpiero.buscarino@unipa.it 


\section{Contents}

1. Supplementary XRD patterns.......................................... S3

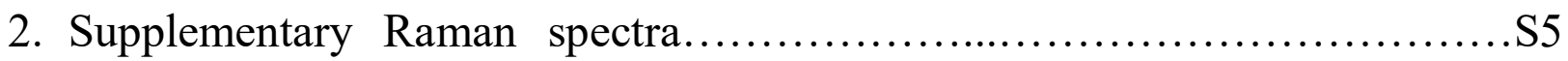

3. Nitrogen isotherms and BET values..................................... 7

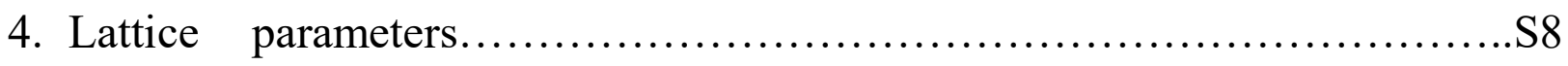

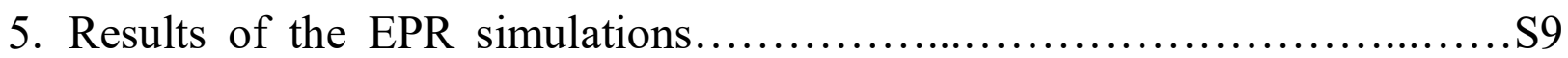




\section{XRD patterns}

Figure S1 shows the powder XRD patterns of STAM-17-OEt at different times of exposure. In the pattern acquired after 1.5 hours of exposure (orange) a superimposition of the peaks of the both the activated and hydrated pattern are evident, in particular in the range $8 \div 20^{\circ}$.
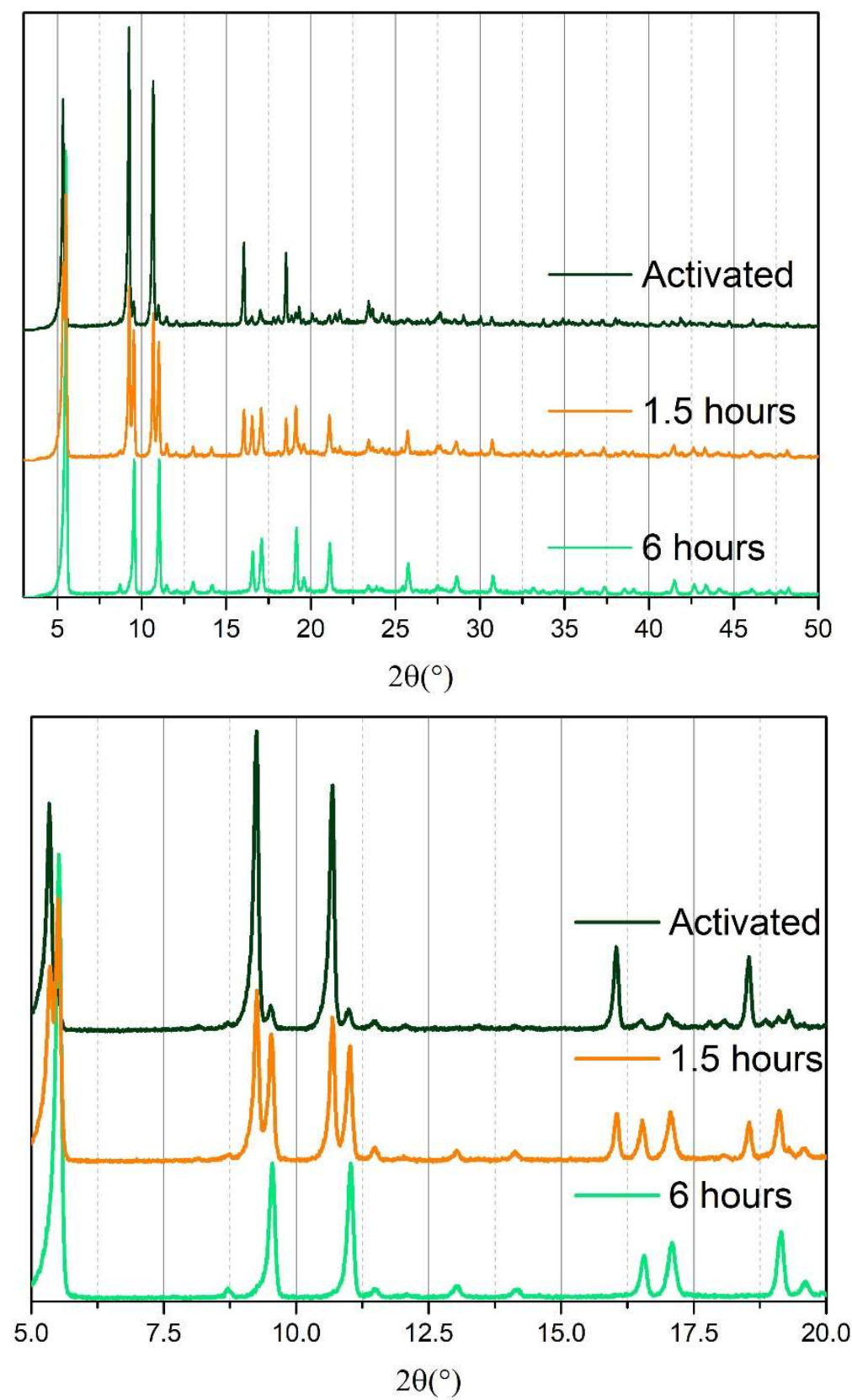

Figure S1 - At the top: powder XRD patterns of STAM-17-OEt activated and after 1.5 and 6 hours of exposure. At the bottom: enlargements of the range $5 \div 20^{\circ}$. 
Figures $\mathrm{S} 2$ and $\mathrm{S} 3$ show the indistinguishability of the lineshapes and intensities in the XRD patterns of the STAM-17-OEt and STAM-1, respectively, before exposure to humidity and after the reactivation at the end of the experiment.

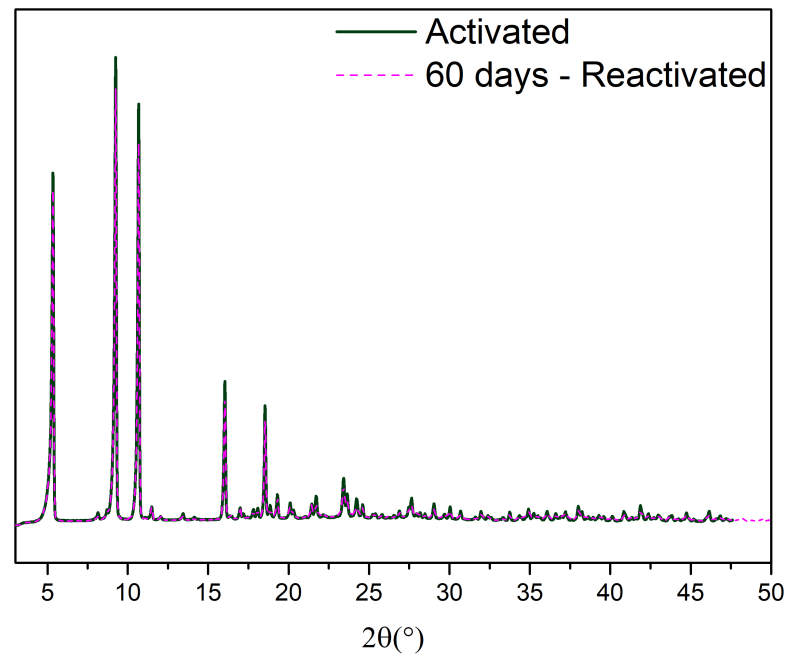

Figure S2 - XRD patterns of STAM-17-OEt before and after the treatments

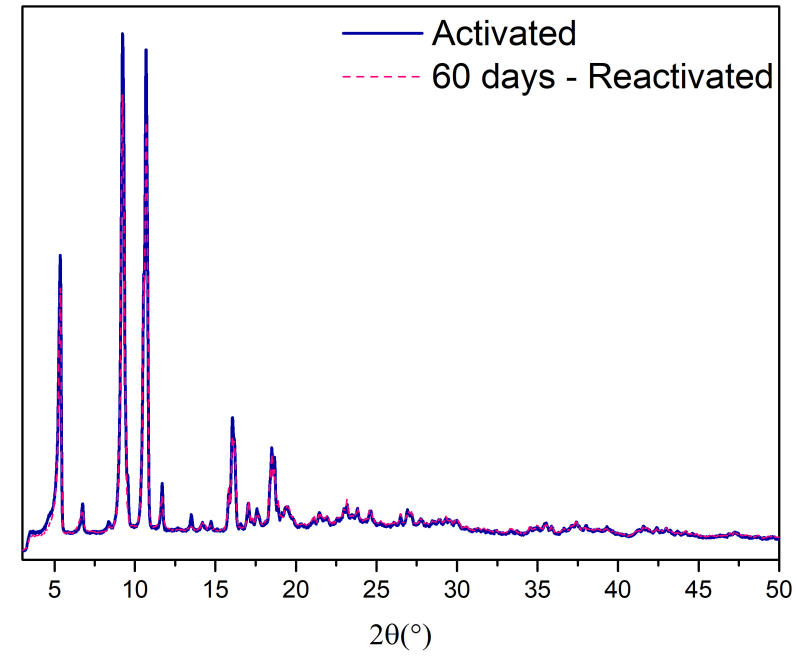

Figure S3 - XRD patterns of STAM-1 before and after the treatments 


\section{Raman spectra.}

Figure S4 shows Raman spectra acquired on different grains of a sample of STAM-17-OEt after 4 days of exposure. In particular, it shows that the change of the intensity of the peaks at 1134 and 1519 $\mathrm{cm}^{-1}$ is not related to the degree of hydration of the material but only to an inhomogeneity of the sample.

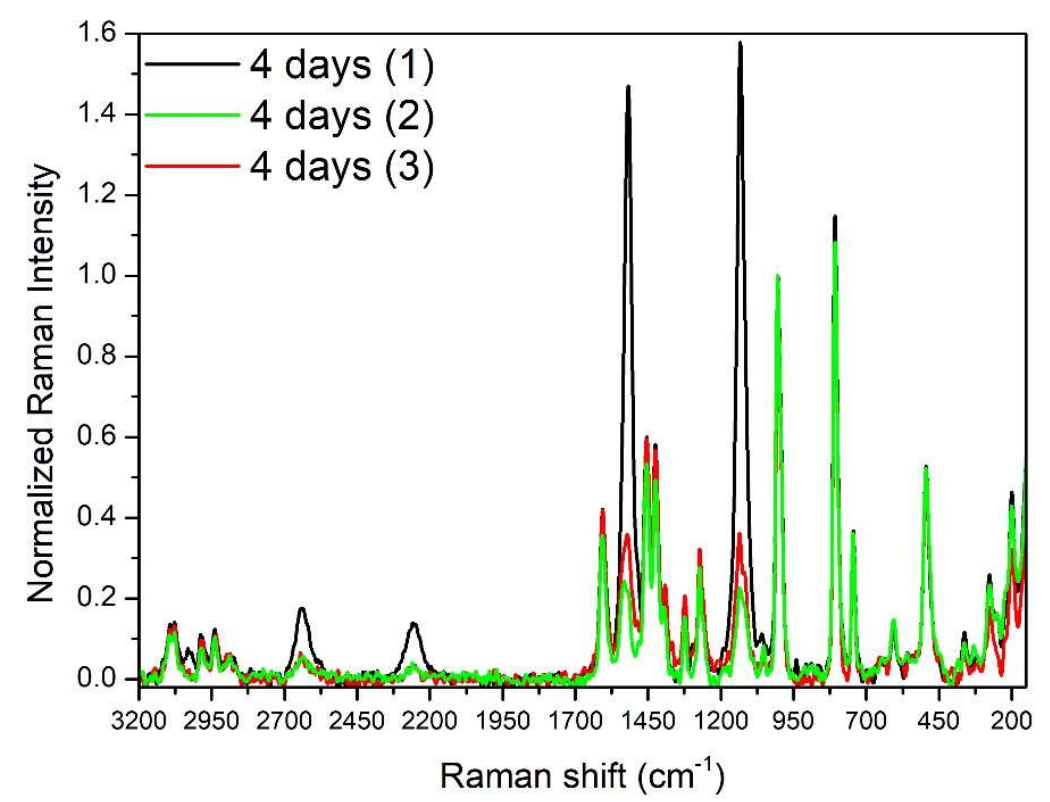

Figure S4 - Raman spectra of STAM-17-OEt after 4 days of exposure acquired in different grains of the material.

Figure S5 shows the Raman spectra of HKUST-1, STAM-17-OEt and STAM-1 acquired before and after the treatments. The activation of the samples during the measurements is preserved thanks to the use of the Linkam cell, that ensures a temperature of $423 \mathrm{~K}$ during all the period of the acquisition. 

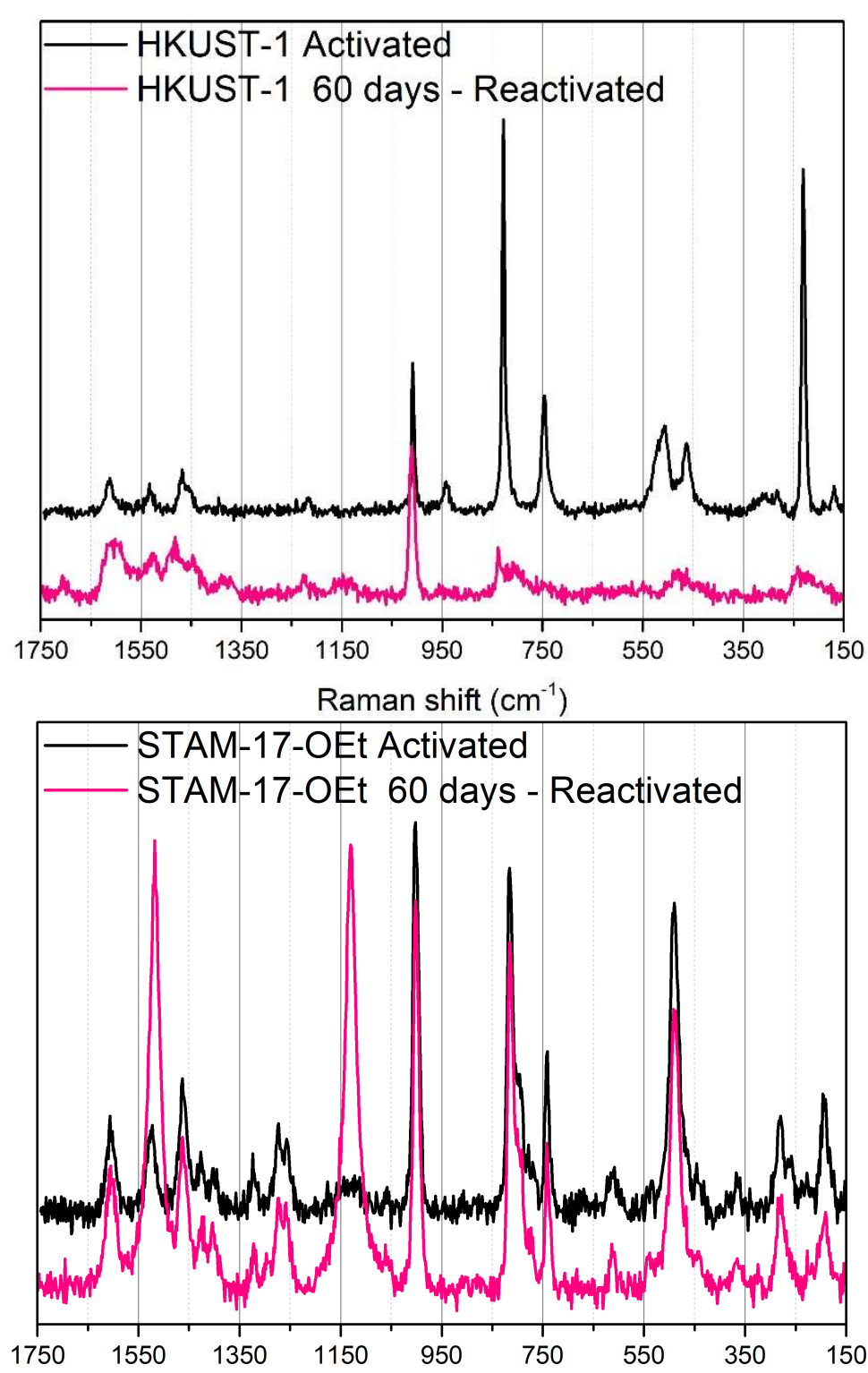

Raman shift $\left(\mathrm{cm}^{-1}\right)$

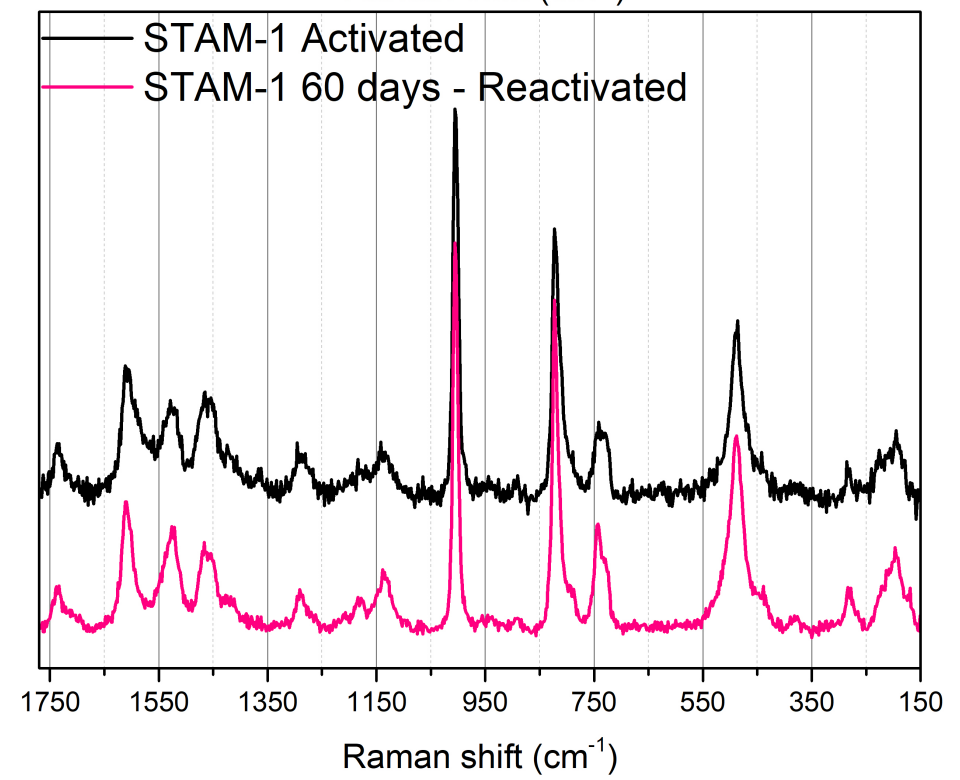




\section{BET}

Table S1 - BET surface areas of HKUST-1, STAM-1 and STAM-17-OEt at different times of exposure.

\begin{tabular}{|l|c|c|c|}
\hline & \multicolumn{3}{|c|}{ BET surface area $\left(\mathbf{m}^{2} / \mathbf{g}\right)$} \\
\hline \multicolumn{1}{|c|}{ Exposure } & HKUST-1 & STAM-1 & STAM-17-OEt \\
Activated & 1662 & 81 & 77 \\
1 day & 860 & 74 & 46 \\
4 days & 26 & 93 & 56 \\
60 days & 62 & 90 & 36 \\
60 days - Reactivated & 62 & 94 & 32 \\
\hline
\end{tabular}
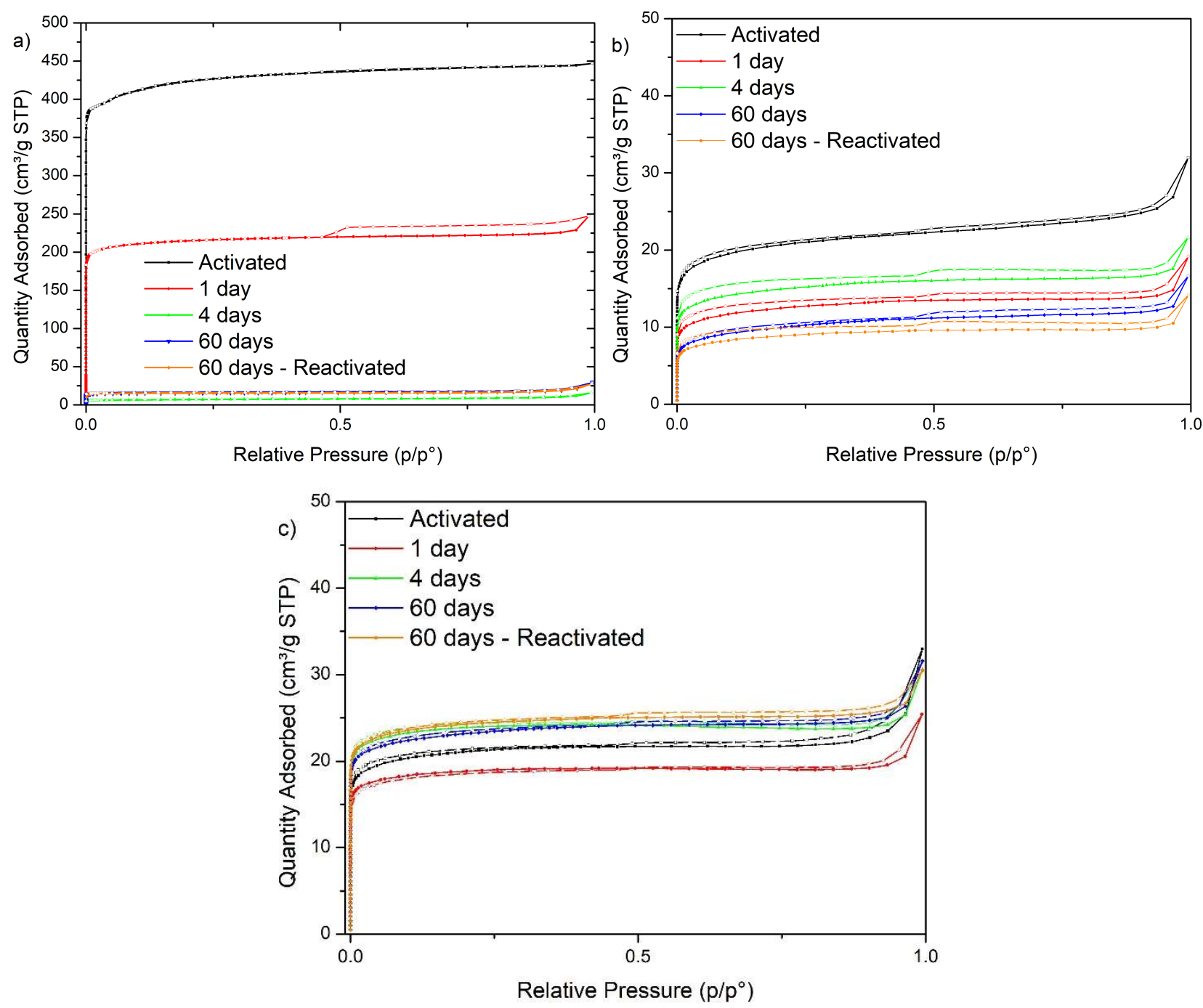

Figure S6 - Nitrogen isotherms of HKUST-1 (a), STAM-1 (b), STAM-17-OEt (c) at different time of exposure. The full symbols correspond to adsorption curves, the empty symbols to the correspondent desorption curves. 


\section{Lattice parameters}

Table S2 - BET surface areas of HKUST-1, STAM-1 and STAM-17-OEt at different times of exposure.

\begin{tabular}{|c|c|c|c|c|}
\hline \multirow{2}{*}{ As made } & \multicolumn{2}{|c|}{ STAM-1 } & \multicolumn{2}{c|}{ STAM-17-OEt } \\
\cline { 2 - 5 } & $a, b$ & $c$ & $a, b$ & $c$ \\
\cline { 2 - 5 } & 18.6861 & 6.8762 & 18.5992 & 6.8221 \\
$\begin{array}{c}\text { After 60 days of } \\
\text { exposure }\end{array}$ & 18.6055 & 6.8847 & 18.5495 & 6.8188 \\
\hline
\end{tabular}

Table S2 shows the lattice parameters obtained for STAM-1 and STAM-17-OEt in two different moments: the "as made" samples represent the materials just after the synthesis and drying procedures but before the activation processes, whereas the samples hydrated for 60 days are the last one that have been measured before the reactivation processes. For sake of clarity the correspondent patterns are shown in Figure S7 and S8:
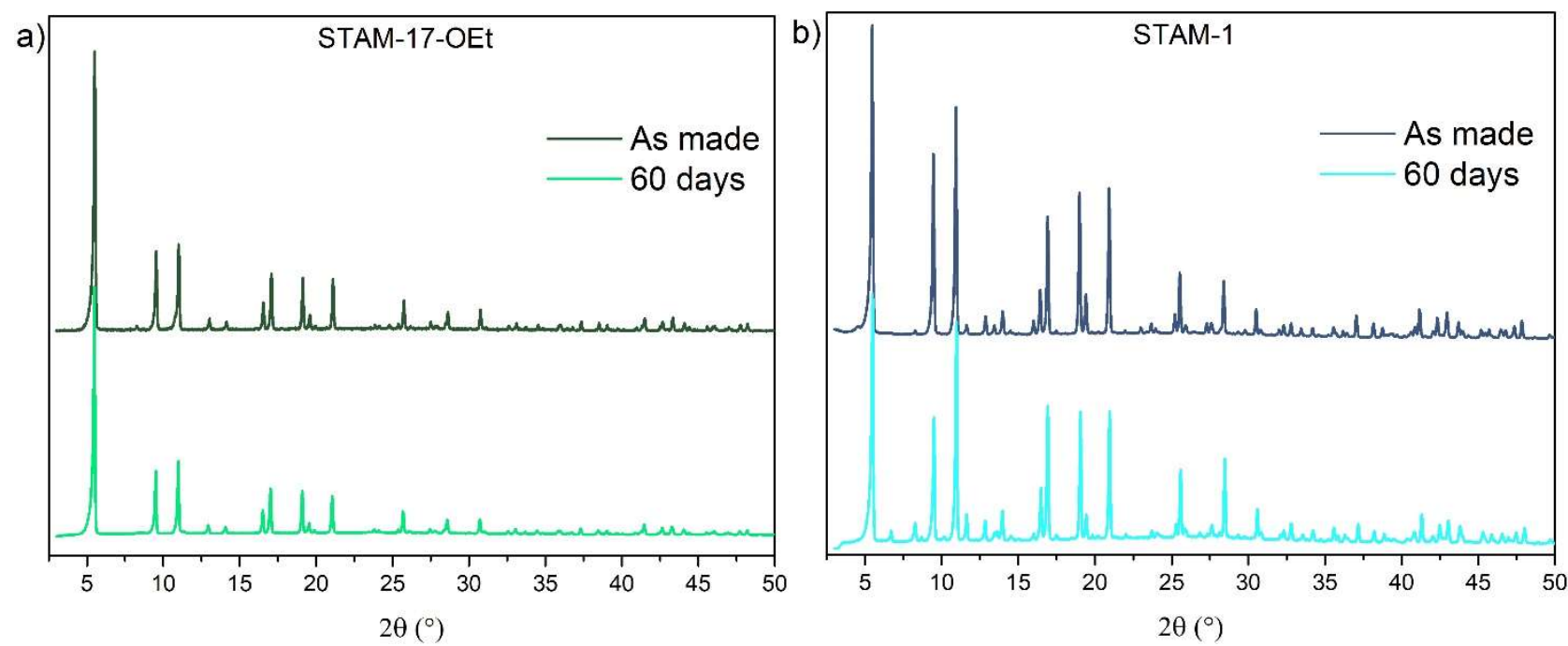

Figure S7 - XRD patterns of STAM-17-OEt (a) and STAM-1 (b) obtained for the samples "as made" and "60 days". 


\section{EPR Simulations}

HKUST-1 activated

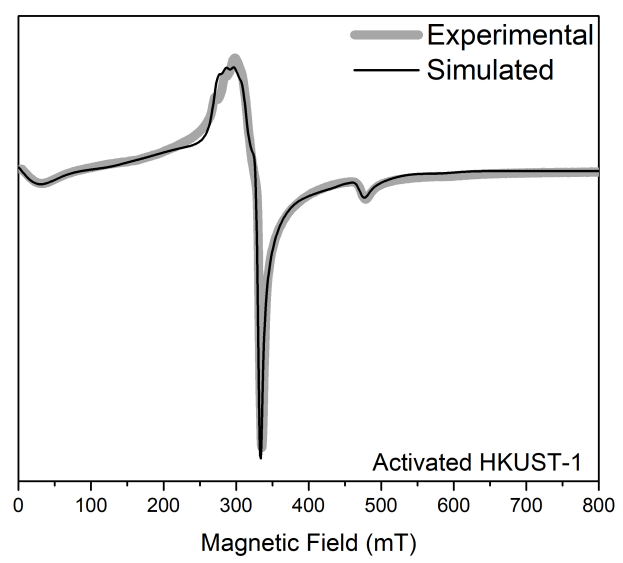

\begin{tabular}{|l|l|l|l|}
\hline $\begin{array}{l}\text { HKUST-1 } \\
\text { Activated }\end{array}$ & $\mathrm{g}$ & gStrain & $\mathrm{D}, \mathrm{E}\left[\mathrm{cm}^{-1}\right]$ \\
\hline \multirow{3}{*}{ Triplet } & 2.04 & 0.07 & 0.321 \\
& 2.04 & 0.59 & $<0.001$ \\
\hline
\end{tabular}

Figure S8 - Comparison between experimental and simulated EPR spectra for activated HKUST-1. Table S3 - Parameters of the simulated EPR spectrum for activated HKUST-1.

HKUST-1 hydrated ( 6 hours)

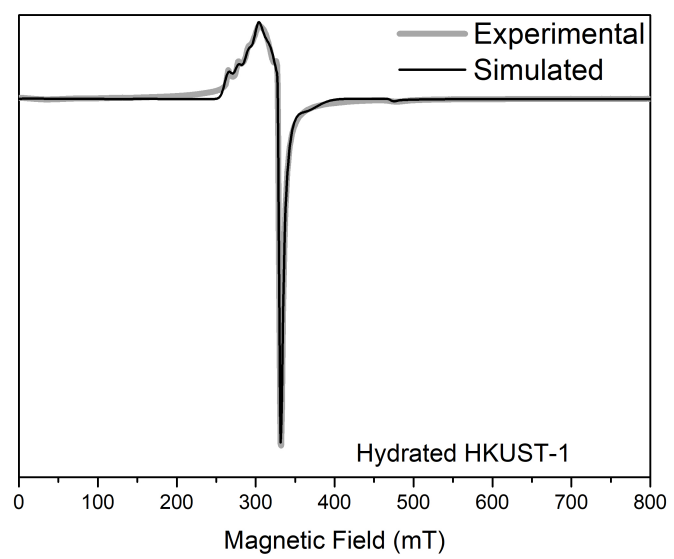

\begin{tabular}{|c|c|c|c|}
\hline $\begin{array}{l}\text { HKUST-1 } \\
\text { Hydrated } 6 \text { hours }\end{array}$ & g & gStrain & $\begin{array}{l}\mathrm{D}, \mathrm{E} \\
{\left[\mathrm{cm}^{-1}\right]}\end{array}$ \\
\hline Triplet & $\begin{array}{l}2.04 \\
2.04 \\
2.36\end{array}$ & $\begin{array}{l}0.07 \\
0.59 \\
0.45\end{array}$ & $\begin{array}{l}0.321 \\
<0.001\end{array}$ \\
\hline Spin $1 / 2$ & $\begin{array}{l}2.07 \\
2.11 \\
2.40 \\
\end{array}$ & $\begin{array}{l}0.01 \\
0.20 \\
0.09 \\
\end{array}$ & // \\
\hline
\end{tabular}

Figure S9 - Comparison between experimental and simulated EPR spectra for hydrated HKUST-1.. Table S4 - Parameters of the simulated EPR spectrum for hydrated HKUST-1.

STAM-1 activated

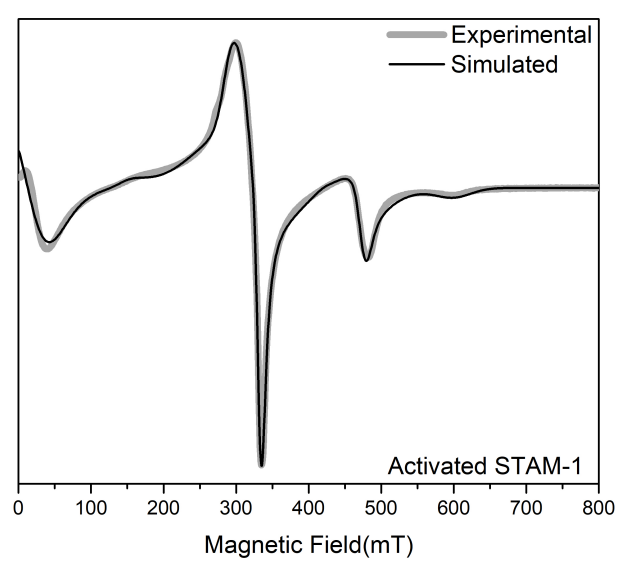

\begin{tabular}{|l|l|l|l|}
\hline STAM-1 & $\mathrm{g}$ & gStrain & $\mathrm{D}, \mathrm{E}\left[\mathrm{cm}^{-1}\right]$ \\
\hline Activated & 2.06 & 0.09 & 0.328 \\
Triplet & 2.06 & 0.71 & 0.002 \\
& 2.32 & 0.45 & \\
\hline
\end{tabular}

Figure S10 - Comparison between experimental and simulated EPR spectra for activated STAM-1.

Table S5 - Parameters of the simulated EPR spectrum for activated STAM-1. 
STAM-1 hydrated (6 hours)

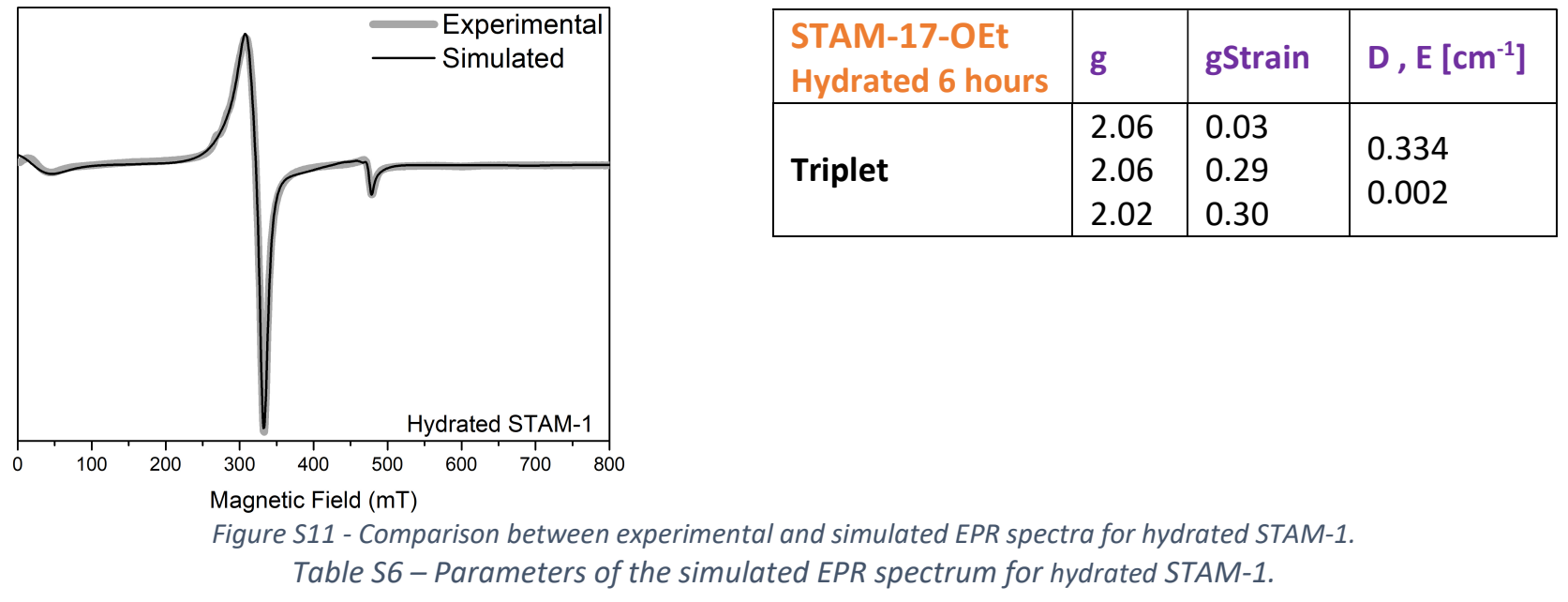

\section{STAM-17-OEt activated}

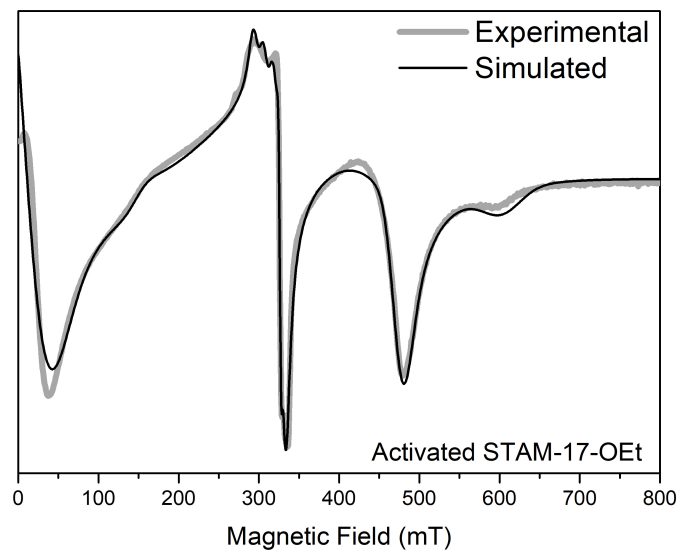

\begin{tabular}{|l|l|l|l|}
\hline $\begin{array}{l}\text { STAM-17-OEt } \\
\text { Activated }\end{array}$ & $\mathrm{g}$ & gStrain & $\mathrm{D}, \mathrm{E}\left[\mathrm{cm}^{-1}\right]$ \\
\hline \multirow{3}{*}{ Triplet } & 2.05 & 0.15 & 0.314 \\
& 2.09 & 0.59 & 0.002 \\
\hline
\end{tabular}

Figure S12 - Comparison between experimental and simulated EPR spectra for activated STAM-17-OEt. Table S7 - Parameters of the simulated EPR spectrum for activated STAM-17-OEt.

\section{STAM-17-OEt hydrated (6 hours)}

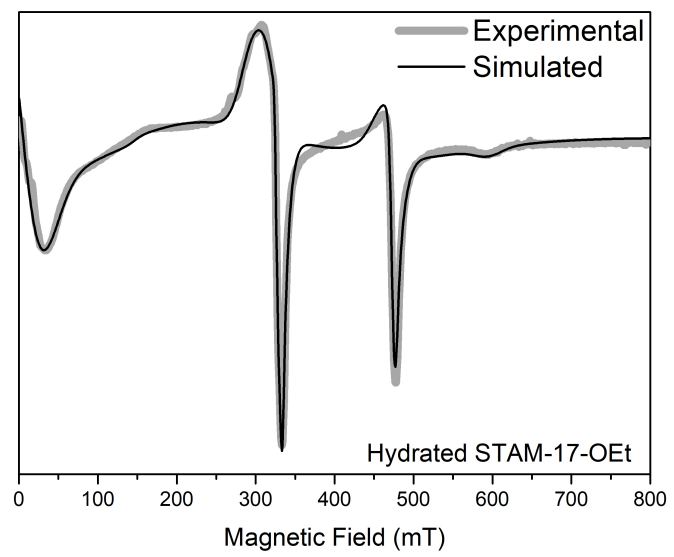

\begin{tabular}{|l|l|l|l|}
\hline $\begin{array}{l}\text { STAM-17-OEt } \\
\text { Hydrated 6 hours }\end{array}$ & $\mathrm{g}$ & gStrain & $\mathrm{D}, \mathrm{E}\left[\mathrm{cm}^{-1}\right]$ \\
\hline & 2.04 & 0.04 & 0.318 \\
Triplet & 2.04 & 0.19 & $<0.001$ \\
\hline
\end{tabular}

Figure S13 - Comparison between experimental and simulated EPR spectra for hydrated STAM-17-OEt. Table 58 - Parameters of the simulated EPR spectrum for hydrated STAM-17-OEt. 